\title{
Emotional impact of health personnel, medical students, and general population samples during COVID-19 pandemic in Lima, Peru: A cross- sectional study.
}

Pedraz-Petrozzi, Bruno ( $\square$ bruno.pedraz@med.uni-giessen.de )

Justus-Liebig University, Giessen

Krüger-Malpartida, Hever

Peruvian University Cayetano Heredia

Arevalo-Flores, Martin

Peruvian University Cayetano Heredia

Salmavides-Cuba, Frine

Peruvian University Cayetano Heredia

Anculle-Arauco, Victor

Peruvian University Cayetano Heredia

Dancuart-Mendoza, Mauricio

Peruvian University Cayetano Heredia

\section{Research Article}

Keywords: COVID-19, mental health, psychiatry, depression, public health

Posted Date: November 11th, 2020

DOI: https://doi.org/10.21203/rs.3.rs-104849/v1

License: (c) (i) This work is licensed under a Creative Commons Attribution 4.0 International License.

Read Full License

Version of Record: A version of this preprint was published at Revista Colombiana de Psiquiatría on July 1st, 2021. See the published version at https://doi.org/10.1016/j.rcp.2021.04.006. 


\section{Abstract}

Background: Negative emotional effects were reported in different groups since the beginning of the COVID-19 pandemic. However, few studies compare those groups regarding the emotional effects of the COVID-19. To this end, this study's main objective is to compare the emotional effects of the COVID-19 between three different groups, namely health personnel, medical students, and the general population sample.

Methods: We recruited 375 participants for this study, of which 125 were medical students (preclinical studies $=59$, clinical studies $=66), 125$ were health personnel $($ COVID-19 first-line personnel $=59$, personnel not related with COVID-19 = 66), and 125 belonged to the general population. PHQ-9 (depression), GAD-7 (anxiety), and CPDI (COVID-19 related stress) were assessed to measure the emotional impact. A multinomial logistic regression was carried out to measure differences between groups, considering possible confounding factors.

Results: Regarding CPDI values, all other groups showed reduced CPDI values compared to COVID-19 first-line personnel. However, the general population, preclinical medical students, and clinical medical students showed increased PHQ-9 values compared to COVID-19 first-line personnel. Finally, confounder factors, gender and age, correlated negatively with higher CPDI and PHQ-9 scores.

Conclusions: Being COVID-19 first-line personnel is associated with more stress related to COVID-19. Depression is associated, however, with other groups not directly involved with the treatment of COVID-19 patients. Female and younger age participants correlated with depression and stress related to COVID-19.

\section{Introduction}

Since the first case reports, the coronavirus disease 2019 (COVID-19) has spread rapidly and has caused different negative changes in the world population. These involved not only social restrictions but also negative consequences for the mental health of society. Different groups, who work actively with COVID$19^{1}$ as those who have to comply with the COVID-19 lockdown rules ${ }^{2}$, are exposed to higher stress, anxiety, and depression rates. For instance, two cross-sectional studies reported that during the COVID-19, pandemic college students reported high levels of mental health distress and academic difficulties ${ }^{3,4}$, reporting a significant negative impact on the mental health of those students ${ }^{3,4}$. Other study in Pakistan, which involved actively COVID-19 frontline health personnel, found higher prevalence rates with moderate-to-severe anxiety and depression scores ${ }^{5}$. Similar results have been found in the study of AlAteeq et al. This study revealed that depression and anxiety symptoms are prevalent between COVID-19 health personnel ${ }^{6}$. Depression and anxiety are not prevalent only in health personnel samples, but also in medical students, which correspond to the health personnel in training. In this case, a study with medical students reported that almost two-thirds of the medical students showed moderate-to-severe depressive symptoms ${ }^{7}$. Besides, the same study found that half of these students showed higher anxiety symptoms. In this case, and similar to the health personnel, medical students are affected severely by 
mental health issues related to COVID-19 pandemic $^{7-9}$. These negative consequences of the COVID-19 pandemics have also affected the general population not related directly to COVID-19. A Peruvian study showed that almost half of the participants showed mild to severe scores related to COVID-19 related stress ${ }^{10}$. Other non-health-workers have reported that spending time with COVID-19 information is associated positively with distress levels ${ }^{11}$. Another example with the general population not related to health professions is the study of Zhang et al. Among the general population during the COVID-19 pandemic, it was found higher levels of depression, mostly related to stress and hopeless feelings ${ }^{12}$.

Pandemics, e.g., the COVID-19, are mostly related to higher rates of depression ${ }^{13-15}$, anxiety 16,17 , and stress ${ }^{18,19}$, reported in general in health personnel and medical students. Despite the numerous reports, few studies compare the mentioned groups. The obtained information in this matter will establish better intervention policies to prioritize the most affected population group, offering medical intervention, social and therapeutic support. To this end, the main objective of this study is to find out differences between medical students, COVID-19 frontline health personnel, health personnel not exposed to COVID-19, and the general population, regarding depression, anxiety, and distress scores.

\section{Materials And Methods}

\subsection{Study design and selection criteria}

For this study, we recruited 375 participants voluntarily from Lima (Peru) between 18 and 80 years old for an online electronic survey. The volunteers included medical students from the faculty of Medicine of the Peruvian University "Cayetano Heredia" (UPCH) and health personnel from Lima's health centers. The participants were recruited between $20^{\text {th }}$ July and $21^{\text {st }}$ September 2020 and allocated into five groups: general population (GP; $n=125)$, medical students in preclinical studies (MS-pre; $n=59$ ), medical students in clinical studies (MS-cli; $n=66$ ), COVID-19 first-line health personnel (HP-COVID; $n=59$ ) and health personnel not involved with COVID-19 patients (HP; $n=66)$. A complete description is shown in Table 1.

Participants younger than 18 years old, with insufficient knowledge of Spanish and medical difficulties that could restrict the participation (i.e., learning difficulties or blindness) in the online survey were not included in this study.

Each participant was fully informed of the study and gave their consent to participate. This study was approved by the ethics committee from the Faculty of Medicine of the Peruvian University Cayetano Heredia and carried out following the Helsinki Declaration and the APA's ethical standards.

\subsection{Data collection}

\subsubsection{Online Survey}


For the data collection, an online electronic survey was carried out. Due to the restrictive policies for avoiding COVID-19 contagions, all instruments and questions were digitalized and programmed in a survey internet-free program (Google Forms). The questions included: informed consent, general information (i.e., age, gender, district, confession/faith, and occupation), previous medical diagnosis and medication intake, and the COVID-19 peri-traumatic distress index (CPDI) for the COVID-19 pandemic, GAD-7, and PHQ-9 instruments.

Finally, additional questions were as follows: "in the last 14 days, did you have a cough, difficulty breathing, sore throat, and fever?" (COVID_1), "do you have positive results for any COVID-19 test?" (COVID_2), "have you been hospitalized (or are you hospitalized at the moment) due to COVID-19?" (COVID_3), "do you have relatives with positive results for any COVID-19 test?" (COVID_4), "do you have relatives who were hospitalized due to COVID-19?" (COVID_5) and "do you have relatives who have passed away due to COVID-19?"' (COVID_6).

\subsubsection{COVID-19 Peritraumatic distress index (CPDI)}

The COVID-19 peritraumatic distress index (CPDI) was first applied in China ${ }^{20}$ and recently validated in other countries ${ }^{21,22}$. This instrument was designed for a population evaluation of changes related to mood, behavior, cognitive skills, circadian rhythm, and other somatic symptoms due to the COVID-19 pandemic.

This instrument consists of 24 items, with a four-factor design: negative mood, cognition, behavioral change, somatization, and hyperarousal/exhaustion. Each item was evaluated by using Likert elements (from 0 to 4: never, occasionally, sometimes, often, and most of the time). The sum of each value per question results in the raw score. The displayed score is obtained by adding 4 to the raw score and used to calculate the CPDI severity degrees. For this reason, this instrument defines different categories for peritraumatic stress due to the COVID-19 pandemic: normal (0 to 28 display points), mild (29 to 52 display points, and severe (53 to 100 display points).

\subsubsection{Depressive and anxiety symptoms}

The Peruvian version of the PHQ-9 ${ }^{23}$ was used to assess the severity of depressive symptoms. The PHQ9 delivers values in the range between 0 and 27. The highest value indicates a higher depression score. This instrument was validated in Peru with a representative sample $(n=30446)$ and showed significant internal consistency (Cronbach's $a=0.87$ ). This inventory defines different categories for depression scores: minimal (1 to 4 points), mild (5 to 9 points), moderate (10 to 14 points), and severe (15 to 27 points).

For anxiety symptoms, the Peruvian version of the GAD-7 ${ }^{24}$ was used to assess the severity of anxiety symptoms. The GAD-7 delivers values in the range between 0 and 21 points. The highest value indicates a higher anxiety score. This instrument was also validated in Peru with a representative sample $(n=$ 2978), showing significant internal consistency (Cronbach's $a=0.89)$. This inventory also defines 
different categories for anxiety scores: minimal (0 to 4 points), mild (5 to 10 points), moderate (11 to 15 points, and severe (16 to 21 points).

\subsubsection{Statistical Analysis}

Statistical analyses were performed using SPSS version 26.0 (Statistical Package for the Social Sciences, International Business Machines Corporation, New York, United States of America) and jamovi 1.2.5.0 25.

Descriptive data were managed with count data and percentages. To improve readability, the information is presented in tables. Quantitative variables approximately fitting a normal distribution are specified in the text as the mean \pm standard deviation $(M \pm S D)$, and those with a non-normal distribution are expressed as the median (Me) with percentile 75 (Q3) and percentile $25(\mathrm{Q} 1)$ and the interquartile range (Q3 - Q1; IQR). Categorical variables were specified with count data and percentages. Data were rounded to the next decimal to obtain results with two decimals. Values smaller than 0.001 were shown as $<0.001$ and values greater than one million were expressed in scientific notation.

Multinomial logistic regression was computed for comparing the five groups, considering the group status (GP, MS-pre, MS-cli, HP or HP-COVID) as a dependent variable. Regarding predictor variables, the following were used as predictor variables and added in four different blocks, as follows:

- Block 1: CPDI scores, GAD-7 scores, PHQ-9 scores.

- Block 2: age, gender, CPDI scores, GAD-7 scores, PHQ-9 scores.

- Block 3: COVID_1, COVID_2, COVID_3, COVID_4,COVID_5, COVID_6, age, gender, CPDI scores, GAD-7 scores, $P H Q-9$ scores.

- Block 4: domicile, confession/faith, medication intake, previous medical disease, COVID_1, COVID_2, COVID_3, COVID_4, COVID_5, COVID_6, age, gender, CPDI scores, GAD-7 scores, PHQ-9 scores.

The "block" that better explained the data was chosen by using the Akaike information criterion (AIC).

The results of this statistical modeling are presented in Table 4. The odds ratio was flagged as "significant" if the two-tailed p-value was smaller than 0.05 . The 95-percent confidence intervals were calculated for this model.

\section{Results}

General sample descriptions, including medication intake and previous clinical diagnoses of the five groups included in the study, are listed in table 1. Previous information regarding COVID-19 infection, including COVID-19 infection on relatives, is represented in table 2. Descriptive data regarding anxiety scores, depression scores, and CPDI scores are presented in table 3.

\subsection{Statistical modeling for emotional impact after COVID-19 lockdown}


This study's objective was to find out differences between the five established groups (i.e. GP, MS-pre, MScli, HP and HP-COVID) regarding depression, anxiety, and distress scores. Variables were introduced stepwise in four different blocks. The block, which best explained the data, was chosen using as criterium a smaller AIC. In this case, Block 2 was chosen as the best model that could better explain the data of the five groups $\left(\right.$ Block 1: $\chi^{2}{ }_{(d f=12)}=63.10, A I C=1139 ; B l o c k 2: \chi^{2}(d f=20)=408.40, A I C=809 ;$ Block 3: $\chi^{2}(d f=$ $44)=442.40, \mathrm{AIC}=823 ;$ Block $\left.4: \chi^{2}(\mathrm{df}=56)=462.10, \mathrm{AIC}=828\right)$. Block 2 included the variables age, gender, $C P D I$ scores, GAD-7 scores, $P H Q-9$ scores as predictors.

Different correlations were found between the five groups. These are presented in Table 4. In summary, being part of the GP correlated positively with higher PHQ-9 values, when compared to the HP-COVID group (GP vs. HP-COVID: OR = 1.15; CI95 [1.03; 1.29]; $\mathrm{p}=0.02$ ). Similar positive correlations were observed in the MS-pre (MS-pre vs. HP-COVID: OR = 1.23; CI95 [1.02; 1.47]; $\mathrm{p}=0.03$ ). Moreover, being part of the MS-cli group correlated with higher PHQ-9 values, when compared to HP-COVID (MS-cli vs. HPCOVID: $\mathrm{OR}=1.17 ; \mathrm{CI} 95[1.01 ; 1.35] ; p=0.03)$. Within those comparisons, significant correlations were found between PHQ-9 scores, gender and age (Table 5).

On the other hand, higher CPDI values correlated negatively in the comparison GP vs. HP-COVID (OR = 0.92; Cl95 [0.88; 0.96]; $p<0.001)$. Similar negative correlations were found also between MS-prevs. HP$\operatorname{COVID}(\mathrm{OR}=0.90 ; \mathrm{Cl} 95[0.84 ; 0.97] ; \mathrm{p}=0.01)$, MS-clivs. HP-COVID $(\mathrm{OR}=0.91 ; \mathrm{Cl} 95[0.86 ; 0.96] ; \mathrm{p}<0.001)$ and HPvs. HP-COVID (OR = 0.94; CI95 [0.90; 0.99]; $\mathrm{p}=0.02)$. Within those comparisons, significant correlations were found between CPDI scores, gender and age (Table 5).

\section{Discussion}

This study results in two different outcomes concerning differences on the emotional impact due to the COVID-19 pandemic between the five groups (i.e. GP, MS-pre, MS-cli, HP, and HP-COVID). On the one hand, this study showed that higher CPDI values correlate with the COVID-19 frontline health personnel compared with the other remaining four groups. On the other hand, the groups GP, MS-pre and MS-cli showed increased PHQ-9 values than COVID-19 frontline health personnel. No correlations were found with the GAD-7 between groups.

Naser et al published a cross-sectional study comparing the adverse effects of the COVID-19 pandemics in three different groups: university students, health care professionals, and the general population. They found that mental health problems (i.e., anxiety and depression) were more prevalent in university students ${ }^{26}$.

In this study, the groups of medical students showed correlations with PHQ-9 values compared to the HPCOVID group. However, no correlations were seen for anxiety scores (Table 4). These outcomes revealing higher depression values among medical students could be due to the social restrictions that obligate many medical students to abandon their studies ${ }^{7,9,27}$. The switch to distance education and the 
suspension of clinical activities or night shifts could have negatively influenced this group's mental health, leading mostly to adverse mood effects ${ }^{7,9,27}$.

Krishnamoorthy et al. published a meta-analysis indicating that during pandemic, health professionals have a higher prevalence of psychological morbidities than the general population, characterized mostly by psychological distress and poor sleep quality ${ }^{28}$. The results of this study support indeed that higher values of psychological distress are correlated to the COVID-19 frontline health personnel group. However, being part of the general population is mostly correlated with higher depression scores. Frontline professionals are confronted most of the time, with fears from getting infected or infecting others ${ }^{28}$. Other concerns, like personal protection, death of their own colleagues, or excess working hours, could have influenced obtained results.

On the other hand, the general population is exposed to isolation due to the sanitary restrictions $10,20,27$. People belonging to the general population are confined in their homes and restricted to the free transit or movement $10,20,27$. This could lead to higher values of depression, poor sleep quality, hopeless feelings, and suicide thoughts 29,30 .

To remark are also the results between HP and HP-COVID (Table 4). In this case, being a COVID-19 frontline health professional is correlated with higher values of psychological distress due to COVID-19. Similar results were found in the study of Cai et al. ${ }^{31}$. In this mentioned study, COVID-19 frontline medical workers have higher rates of any medical problem than non-frontline medical workers ${ }^{31}$. Cai et al. found correlations between anxiety and depressive symptoms with being frontline health professionals ${ }^{31}$. These findings did not find any correlation between being a frontline health professional and depression or anxiety scores. This could mean that most non-frontline health professionals could comprehend the actual COVID-19 pandemic situation and accomplish the sanitary emergency rules, although they are health professionals.

Finally, the variables age and gender are essential to mention. Significant correlations with the variables age and gender were found in the comparisons (Table 4, Table 5). This could mean that age and gender could also have influenced in the correlations found by this multinomial logistic regression. In this case, younger age or female gender correlated with higher scores of the mentioned psychological instruments (i.e. PHQ-9 and CPDI). These obtained results agreed with other studies that have found associations with female gender and age of the participant $22,26,32,33$.

Although these results contribute to the actual COVID-19 pandemic's panorama, concerning mostly adverse effects on mental health as an emotional impact, the reader must consider some limitations. As always, the sample size could be larger to generalize the results beyond the study's context. However, the power obtained from this study with 375 participants and five groups was $1-\beta=0.93$, a value that overcame the $1-\beta=0.80$ threshold. Therefore, the sample size for the study design should be sufficient to examine the expected effects. Then, the higher total number of women compared to men could have influenced the results. However, studies related to COVID-19 lockdown distress have also reported a 
higher proportion of female participants, which is also reflected in this study. As expected, there were many very low CPDI, PHQ-9 and GAD-7 scores in the evaluated participants, which led to skewed distributions. Multinomial logistic regression was computed to overcome this limitation because there is no consideration regarding skewed statistical distributions. Finally, medication intake, previous medical conditions, and district could affect COVID-19 distress scores. All these variables were included in the model. However, these variables did not appear to affect the results of the current study.

In conclusion, being COVID-19 frontline health personnel is associated with more psychological distress related to COVID-19, involving harmful behavioral and emotional components. This could be related to the fact that frontline health professionals confront excess working hours, their colleagues' death, fear of being infected, etc. On the other hand, higher depression scores were associated mostly with other groups not directly involved with COVID-19 patients' treatment. This could be related to the sanitary emergency restrictions, the long-lasting isolation, the restriction of free movement, and the limitation of different activities, like studying and accomplishing essential duties (in medical students). Finally, female and younger age participants correlated with depression and stress related to COVID-19, playing also an important role on these findings.

\section{Declarations}

\section{Competing interests:}

The authors declare no competing interests.

\section{References}

1. Teng, Z. et al. Mental health of frontline staff in prevention of coronavirus disease 2019. Zhong nan da xue xue bao. Yi xue ban = J. Cent. South Univ. Med. Sci. (2020).

2. Zhou, Y., Macgeorge, E. L. \& Myrick, J. G. Mental health and its predictors during the early months of the covid-19 pandemic experience in the United States. Int. J. Environ. Res. Public Health (2020). doi:10.3390/ijerph17176315

3. Kecojevic, A., Basch, C. H., Sullivan, M. \& Davi, N. K. The impact of the COVID-19 epidemic on mental health of undergraduate students in New Jersey, cross-sectional study. PLoS One (2020). doi:10.1371/journal.pone.0239696

4. Hubner, C. von K., Bruscatto, M. L. \& Lima, R. D. Distress among Brazilian university students due to the Covid-19 pandemic: survey results and reflections. medRxiv (2020).

5. Amin, F., Sharif, S., Saeed, R., Durrani, N. \& Jilani, D. COVID-19 pandemic- knowledge, perception, anxiety and depression among frontline doctors of Pakistan. BMC Psychiatry (2020). doi:10.1186/s12888-020-02864-x

6. AlAteeq, D. A., Aljhani, S., Althiyabi, I. \& Majzoub, S. Mental health among healthcare providers during coronavirus disease (COVID-19) outbreak in Saudi Arabia. J. Infect. Public Health (2020). 
doi:10.1016/j.jiph.2020.08.013

7. Sartorao Filho, C. I. et al. IMPACT OF COVID-19 PANDEMIC ON MENTAL HEALTH OF MEDICAL STUDENTS:A CROSS-SECTIONAL STUDY USING GAD-7 AND PHQ-9 QUESTIONNAIRES. medRxiv (2020).

8. Komer, L. COVID-19 amongst the Pandemic of Medical Student Mental Health. Int. J. Med. Students (2020). doi:10.5195/ijms.2020.501

9. Chandratre, S. Medical Students and COVID-19: Challenges and Supportive Strategies. J. Med. Educ. Curric. Dev. (2020). doi:10.1177/2382120520935059

10. Krüger-Malpartida, H., Pedraz-Petrozzi, B., Arevalo-Flores, M., Anculle-Arauco, V. \& Dancuart-Mendoza, $M$. Effects on the mental health after COVID-19 lockdown period: results from a population survey study in Lima, Peru (PREPRINT). Res. Sq. (2020).

11. Ruiz-Frutos, C. et al. Information on COVID-19 and psychological distress in a sample of non-health workers during the pandemic period. in International Journal of Environmental Research and Public Health (2020). doi:10.3390/ijerph17196982

12. Zhang, W. et al. Depression and Psychological-Behavioral Responses Among the General Public in China During the Early Stages of the COVID-19 Pandemic: Survey Study. J. Med. Internet Res. (2020). doi:10.2196/22227

13. Ho, C. S., Chee, C. Y. \& Ho, R. C. Mental Health Strategies to Combat the Psychological Impact of COVID-19 Beyond Paranoia and Panic. Ann. Acad. Med. Singapore (2020).

14. Liu, X. et al. Depression after exposure to stressful events: Lessons learned from the severe acute respiratory syndrome epidemic. Compr. Psychiatry (2012). doi:10.1016/j.comppsych.2011.02.003

15. Hawryluck, L. et al. SARS control and psychological effects of quarantine, Toronto, Canada. Emerg. Infect. Dis. (2004). doi:10.3201/eid1007.030703

16. Jeong, H. et al. Mental health status of people isolated due to Middle East Respiratory Syndrome. Epidemiol. Health (2016). doi:10.4178/epih.e2016048

17. Lai, J. et al. Factors Associated With Mental Health Outcomes Among Health Care Workers Exposed to Coronavirus Disease 2019. JAMA Netw. Open 3, e203976 (2020).

18. Wang, C. et al. Immediate psychological responses and associated factors during the initial stage of the 2019 coronavirus disease (COVID-19) epidemic among the general population in China. Int. J. Environ. Res. Public Health (2020). doi:10.3390/ijerph17051729

19. Mihashi, M. et al. Predictive Factors of Psychological Disorder Development During Recovery Following SARS Outbreak. Heal. Psychol. (2009). doi:10.1037/a0013674

20. Qiu, J. et al. A nationwide survey of psychological distress among Chinese people in the COVID-19 epidemic: implications and policy recommendations. Gen. Psychiatry 33, e100213 (2020).

21. Afshar Jahanshahi, A., Mokhtari Dinani, M., Nazarian Madavani, A., Li, J. \& Zhang, S. X. The distress of Iranian adults during the Covid-19 pandemic - More distressed than the Chinese and with different predictors. medRxiv 2020.04.03.20052571 (2020). doi:10.1101/2020.04.03.20052571 
22. Zhang, S., Yifei, W., Afshar Jahanshahi, A., Jia, J. \& Haensel-Schmitt, V. First study on mental distress in Brazil during the COVID-19 crisis. medR (2020). doi:10.1101/2020.04.18.20070896

23. Villarreal-Zegarra, D., Copez-Lonzoy, A., Bernabé-Ortiz, A., Melendez-Torres, G. J. \& Bazo-Alvarez, J. C. Valid group comparisons can be made with the Patient Health Questionnaire (PHQ-9): A measurement invariance study across groups by demographic characteristics. PLoS One (2019). doi:10.1371/journal.pone.0221717

24. Zhong, Q. Y. et al. Diagnostic validity of the generalized anxiety disorder - 7 (GAD-7) among pregnant women. PLoS One (2015). doi:10.1371/journal.pone.0125096

25. Love, J. et al. The jamovi project. (2020). Available at: https://www.jamovi.org. (Accessed: 22nd June 2020)

26. Naser, A. Y. et al. Mental health status of the general population, healthcare professionals, and university students during 2019 coronavirus disease outbreak in Jordan: A cross-sectional study. Brain Behav. (2020). doi:10.1002/brb3.1730

27. Alkhamees, A. A., Alrashed, S. A., Alzunaydi, A. A., Almohimeed, A. S. \& Aljohani, M. S. The psychological impact of COVID-19 pandemic on the general population of Saudi Arabia. Compr. Psychiatry (2020). doi:10.1016/j.comppsych.2020.152192

28. Krishnamoorthy, Y., Nagarajan, R., Saya, G. K. \& Menon, V. Prevalence of psychological morbidities among general population, healthcare workers and COVID-19 patients amidst the COVID-19 pandemic: A systematic review and meta-analysis. Psychiatry Res. 293, 113382 (2020).

29. Gunnell, D. et al. Suicide risk and prevention during the COVID-19 pandemic. The Lancet Psychiatry (2020). doi:10.1016/S2215-0366(20)30171-1

30. Kawohl, W. \& Nordt, C. COVID-19, unemployment, and suicide. The Lancet Psychiatry (2020). doi:10.1016/S2215-0366(20)30141-3

31. Cai, Q. et al. The mental health of frontline and non-frontline medical workers during the coronavirus disease 2019 (COVID-19) outbreak in China: A case-control study. J. Affect. Disord. 275, 210-215 (2020).

32. Mazza, C. et al. A nationwide survey of psychological distress among italian people during the covid19 pandemic: Immediate psychological responses and associated factors. Int. J. Environ. Res. Public Health (2020). doi:10.3390/ijerph17093165

33. Losada-Baltar, A. et al. 'We're staying at home'. Association of self-perceptions of aging, personal and family resources and loneliness with psychological distress during the lockdown period of COVID-19. J. Gerontol. B. Psychol. Sci. Soc. Sci. (2020). doi:10.1093/geronb/gbaa048

\section{Tables}

Table 1 - general socio-demographic data 


\begin{tabular}{|c|c|c|c|c|c|}
\hline & $\begin{array}{l}\text { GP }(n= \\
125)\end{array}$ & $\begin{array}{l}\text { MS-pre }(n \\
=59)\end{array}$ & $\begin{array}{l}\text { MS-cli }(n \\
=66)\end{array}$ & $\mathrm{HP}(n=66)$ & $\begin{array}{l}\text { HP-COVID }(n \\
=59)\end{array}$ \\
\hline \multicolumn{6}{|l|}{ Age } \\
\hline Mean \pm SD & $\begin{array}{l}41.10 \pm \\
14.30\end{array}$ & $\begin{array}{l}19.70 \pm \\
2.15\end{array}$ & $\begin{array}{l}23.30 \pm \\
1.74\end{array}$ & $\begin{array}{l}39.60 \pm \\
11.90\end{array}$ & $35.00 \pm 9.41$ \\
\hline Median (Q3 - Q1) & $\begin{array}{l}41(54- \\
29)\end{array}$ & $19(20-19)$ & $\begin{array}{l}23(24- \\
22)\end{array}$ & $\begin{array}{l}38(49.00- \\
31.30)\end{array}$ & $\begin{array}{l}32(37.50- \\
29.00)\end{array}$ \\
\hline Skewness & 0.39 & 3.59 & 1.84 & 0.64 & 1.03 \\
\hline \multicolumn{6}{|l|}{ Gender } \\
\hline Female & $\begin{array}{l}78 \\
(62.40 \%)\end{array}$ & $\begin{array}{l}28 \\
(47.46 \%)\end{array}$ & $\begin{array}{l}40 \\
(60.61 \%)\end{array}$ & $43(65.15 \%)$ & 25 (42.37\%) \\
\hline Male & $\begin{array}{l}47 \\
(37.60 \%)\end{array}$ & $\begin{array}{l}31 \\
(52.54 \%)\end{array}$ & $\begin{array}{l}26 \\
(39.39 \%)\end{array}$ & $23(34.85 \%)$ & $34(57.63 \%)$ \\
\hline \multicolumn{6}{|l|}{ Domicile } \\
\hline Lima - peripheral & $\begin{array}{l}35 \\
(28.00 \%)\end{array}$ & $\begin{array}{l}25 \\
(42.37 \%)\end{array}$ & $\begin{array}{l}23 \\
(34.85 \%)\end{array}$ & $14(21.21 \%)$ & 19 (32.20\%) \\
\hline Lima - center & $\begin{array}{l}90 \\
(72.00 \%)\end{array}$ & $\begin{array}{l}34 \\
(57.63 \%)\end{array}$ & $\begin{array}{l}43 \\
(65.15 \%)\end{array}$ & $52(78.79 \%)$ & $40(67.80 \%)$ \\
\hline \multicolumn{6}{|c|}{ Faith/religious beliefs } \\
\hline Absent & $\begin{array}{l}26 \\
(20.80 \%)\end{array}$ & $\begin{array}{l}30 \\
(50.85 \%)\end{array}$ & $\begin{array}{l}29 \\
(43.94 \%)\end{array}$ & $19(28.79 \%)$ & $14(23.73 \%)$ \\
\hline Present & $\begin{array}{l}99 \\
(79.20 \%)\end{array}$ & $\begin{array}{l}29 \\
(49.15 \%)\end{array}$ & $\begin{array}{l}37 \\
(56.06 \%)\end{array}$ & 47 (71.21\%) & 45 (76.27\%) \\
\hline \multicolumn{6}{|l|}{ Medication intake } \\
\hline No & $\begin{array}{l}54 \\
(43.20 \%)\end{array}$ & $\begin{array}{l}35 \\
(59.32 \%)\end{array}$ & $\begin{array}{l}35 \\
(53.03 \%)\end{array}$ & $42(63.64 \%)$ & 37 (62.71\%) \\
\hline Yes & $\begin{array}{l}71 \\
(56.80 \%)\end{array}$ & $\begin{array}{l}24 \\
(40.68 \%)\end{array}$ & $\begin{array}{l}31 \\
(46.97 \%)\end{array}$ & $24(36.36 \%)$ & 22 (37.29\%) \\
\hline \multicolumn{6}{|c|}{$\begin{array}{l}\text { Presence of past medical } \\
\text { diseases }\end{array}$} \\
\hline No & $\begin{array}{l}83 \\
(66.40 \%)\end{array}$ & $\begin{array}{l}48 \\
(81.36 \%)\end{array}$ & $\begin{array}{l}35 \\
(53.03 \%)\end{array}$ & 47 (71.21\%) & 38 (64.41\%) \\
\hline Yes & $\begin{array}{l}42 \\
(33.60 \%)\end{array}$ & $\begin{array}{l}11 \\
(18.64 \%)\end{array}$ & $\begin{array}{l}31 \\
(46.97 \%)\end{array}$ & $19(28.79 \%)$ & 21 (35.59\%) \\
\hline
\end{tabular}


Abbreviations - GP: general population; MS-pre: medical students, pre-clinical studies; MS-cli: medical students, clinical studies; HP: health personnel (not COVID-19 frontline health personnel); HP-COVID: COVID-19 frontline health personnel.

Table 2 - general COVID-19 information 

GP $(n=$
$125)$
MS-pre $(n$
$=59)$
MS-cli $(n$
$=66$ )
$\underset{66)}{\operatorname{HP}}(n=$
HP-
COVID
$(n=59)$

COVID_1: in the last 14 days, did you have cough, difficulty breathing, sore throat and fever?

$\begin{array}{llllll}\text { No } & 115 & 51 & 57 & 58 & 50 \\ & (92.00 \%) & (86.44 \%) & (86.36 \%) & (87.88 \%) & (84.75 \%) \\ \text { Yes } & 10 & 8 & 9 & 8 & 9 \\ & (8.00 \%) & (13.56 \%) & (13.64 \%) & (12.12 \%) & (15.25 \%)\end{array}$

COVID_2: do you have positive

results for any sort of COVID-19 test?

$\begin{array}{llllll}\text { No } & 119 & 59 & 62 & 60 & 49 \\ & (95.20 \%) & (100.00 \%) & (93.94 \%) & (90.91 \%) & (83.05 \%) \\ \text { Yes } & 6 & 0(0.00 \%) & 4(6.06 \%) & 6 & 10 \\ & (4.80 \%) & & & (9.09 \%) & (16.95 \%)\end{array}$

COVID_3: have you been

hospitalized (or are you hospitalized

at the moment) due to COVID-19?

$\begin{array}{llllll}\text { No } & 124 & 59 & 66 & 64 & 58 \\ & (99.20 \%) & (100.00 \%) & (100.00 \%) & (96.97 \%) & (98.31 \%) \\ \text { Yes } & 1 & 0(0.00 \%) & 0(0.00 \%) & 2 & 1 \\ & (0.80 \%) & & & (3.03 \%) & (1.69 \%)\end{array}$

COVID_4: do you have relatives with

positive results for any sort of COVID-

19 test?

$\begin{array}{llllll}\text { No } & 89 & 25 & 30 & 40 & 28 \\ & (71.20 \%) & (42.37 \%) & (45.45 \%) & (60.61 \%) & (47.46 \%) \\ \text { Yes } & 36 & 34 & 36 & 26 & 31 \\ & (28.80 \%) & (57.63 \%) & (54.55 \%) & (39.39 \%) & (52.54 \%)\end{array}$

COVID_5: do you have relatives who were hospitalized due to COVID-19?

$\begin{array}{llllll}\text { No } & 110 & 44 & 49 & 57 & 46 \\ & (88.00 \%) & (74.58 \%) & (74.24 \%) & (86.36 \%) & (77.97 \%) \\ \text { Yes } & 15 & 15 & 17 & 9 & 13 \\ & (12.00 \%) & (25.42 \%) & (25.76 \%) & (13.64 \%) & (22.03 \%)\end{array}$

COVID_6: do you have relatives who have passed away due to COVID-19?

No

$\begin{array}{lllll}112 & 43 & 54 & 58 & 50 \\ (89.60 \%) & (72.88 \%) & (81.82 \%) & (87.88 \%) & (84.75 \%)\end{array}$


Abbreviations - GP: general population; MS-pre: medical students, pre-clinical studies; MS-cli: medical students, clinical studies; HP: health personnel (not COVID-19 frontline health personnel); HP-COVID: COVID-19 frontline health personnel.

Table 3 - CPDI, PHQ-9 and GAD-7 descriptive data 


\begin{tabular}{|c|c|c|c|c|c|}
\hline & $\begin{array}{l}\text { GP }(n= \\
125)\end{array}$ & $\begin{array}{l}\text { MS-pre }(n= \\
59)\end{array}$ & $\begin{array}{l}\text { MS-cli }(n= \\
66)\end{array}$ & $\mathrm{HP}(n=66)$ & $\begin{array}{l}\mathrm{HP}-\mathrm{COVID}(n= \\
59)\end{array}$ \\
\hline \multicolumn{6}{|l|}{ CPDI } \\
\hline Mean \pm SD & $\begin{array}{l}27.50 \pm \\
13.00\end{array}$ & $33.60 \pm 12.90$ & $28.70 \pm 14.20$ & $26.10 \pm 15.10$ & $30.30 \pm 13.20$ \\
\hline $\begin{array}{l}\text { Median (Q3 - } \\
\text { Q1) }\end{array}$ & $\begin{array}{l}26(36- \\
17)\end{array}$ & $\begin{array}{l}33(43.50- \\
23.50)\end{array}$ & $\begin{array}{l}27(36.80- \\
16.50)\end{array}$ & $\begin{array}{l}22.50(35 \text { - } \\
14.30)\end{array}$ & $29(39-21)$ \\
\hline Skewness & 0.63 & 0.20 & 0.75 & 1.30 & 0.30 \\
\hline \multicolumn{6}{|l|}{ Categories } \\
\hline Normal & 71 & 22 & 37 & 42 & 29 \\
\hline Mild & 47 & 34 & 25 & 22 & 26 \\
\hline Severe & 7 & 3 & 4 & 2 & 4 \\
\hline \multicolumn{6}{|l|}{ PHQ-9 } \\
\hline Mean \pm SD & $\begin{array}{l}5.22 \pm \\
5.28\end{array}$ & $9.59 \pm 6.20$ & $7.32 \pm 5.48$ & $4.14 \pm 4.66$ & $4.73 \pm 4.40$ \\
\hline $\begin{array}{l}\text { Median (Q3 - } \\
\text { Q1) }\end{array}$ & $4(8-1)$ & $8(13-5)$ & $6(11-3)$ & $3(6-0.25)$ & $4(7-1)$ \\
\hline Skewness & 1.24 & 0.81 & 0.78 & 1.66 & 1.18 \\
\hline \multicolumn{6}{|l|}{ Categories } \\
\hline Minimal & 67 & 12 & 21 & 43 & 30 \\
\hline Mild & 37 & 23 & 26 & 14 & 21 \\
\hline Moderate & 13 & 12 & 10 & 6 & 7 \\
\hline Severe & 8 & 12 & 9 & 3 & 1 \\
\hline \multicolumn{6}{|l|}{ GAD-7 } \\
\hline Mean \pm SD & $\begin{array}{l}4.46 \pm \\
3.68\end{array}$ & $6.66 \pm 4.44$ & $5.45 \pm 4.54$ & $3.76 \pm 3.60$ & $4.32 \pm 3.74$ \\
\hline $\begin{array}{l}\text { Median (Q3 - } \\
\text { Q1) }\end{array}$ & $4(7-1)$ & $7(8.50-3.50)$ & $5(7-2)$ & $3(6-1)$ & $4(6.00-1.50)$ \\
\hline Skewness & 1.04 & 0.78 & 1.26 & 1.36 & 1.48 \\
\hline \multicolumn{6}{|l|}{ Categories } \\
\hline Minimal & 66 & 19 & 32 & 39 & 35 \\
\hline Mild & 52 & 32 & 26 & 24 & 22 \\
\hline Moderate & 4 & 4 & 5 & 2 & 0 \\
\hline
\end{tabular}


Abbreviations - GP: general population; MS-pre: medical students, pre-clinical studies; MS-cli: medical students, clinical studies; HP: health personnel (not COVID-19 frontline health personnel); HP-COVID: COVID-19 frontline health personnel; CPDI: COVID-19 Peritraumatic distress index; PHQ-9: Patient health questionnaire 9; GAD-7: general anxiety disorder questionnaire 7; SD: Standard deviation; Q3: $75^{\text {th }}$ percentile; Q1: $25^{\text {th }}$ percentile.

\section{Table 4 - Multinomial logistic regression}




\begin{tabular}{|c|c|c|c|c|c|}
\hline & Predictor & $p$ & OR & 95\% Cl Lower & 95\% Cl Upper \\
\hline \multirow{5}{*}{$\begin{array}{l}\text { GP (1) vs. MS-pre (0) } \\
\text { (reference level: MS-pre) }\end{array}$} & CPDI scores & 0.58 & 1.02 & 0.95 & 1.10 \\
\hline & GAD-7 scores & 0.70 & 0.96 & 0.77 & 1.20 \\
\hline & PHQ-9 scores & 0.47 & 0.94 & 0.79 & 1.11 \\
\hline & $\mathrm{Age}^{*}$ & $<0.001$ & 3.57 & 2.64 & 4.82 \\
\hline & Gender & 0.27 & 0.52 & 0.16 & 1.67 \\
\hline \multirow{5}{*}{$\begin{array}{l}\text { GP (1) vs. MS-cli (0) } \\
\text { (reference level: MS-cli) }\end{array}$} & CPDI scores & 0.56 & 1.02 & 0.96 & 1.07 \\
\hline & GAD-7 scores & 0.89 & 0.99 & 0.84 & 1.17 \\
\hline & PHQ-9 scores & 0.83 & 0.99 & 0.87 & 1.12 \\
\hline & $\mathrm{Age}^{*}$ & $<0.001$ & 1.59 & 1.39 & 1.81 \\
\hline & gender & 0.84 & 1.09 & 0.47 & 2.57 \\
\hline \multirow{5}{*}{$\begin{array}{l}G P(1) \text { vs. HP (0) } \\
\text { (reference level: HP) }\end{array}$} & CPDI scores & 0.28 & 0.98 & 0.94 & 1.02 \\
\hline & GAD-7 scores & 0.42 & 1.07 & 0.91 & 1.25 \\
\hline & PHQ-9 scores & 0.16 & 1.08 & 0.97 & 1.21 \\
\hline & age & 0.13 & 1.02 & 0.99 & 1.05 \\
\hline & gender & 0.50 & 1.25 & 0.66 & 2.39 \\
\hline \multirow{5}{*}{$\begin{array}{l}\text { GP (1) vs. HP-COVID (0) } \\
\text { (reference level: HP-COVID) }\end{array}$} & CPDI scores* & $<0.001$ & 0.92 & 0.88 & 0.96 \\
\hline & GAD-7 scores & 0.09 & 1.15 & 0.98 & 1.34 \\
\hline & PHQ-9 scores* & 0.02 & 1.15 & 1.03 & 1.29 \\
\hline & $\mathrm{Age}^{\star}$ & $<0.001$ & 1.06 & 1.02 & 1.09 \\
\hline & Gender* & 0.01 & 0.41 & 0.21 & 0.82 \\
\hline \multirow{5}{*}{$\begin{array}{l}\text { MS-pre (1) vs. MS-cli (0) } \\
\text { (reference level: MS-cli) }\end{array}$} & CPDI scores & 0.88 & 1.00 & 0.94 & 1.06 \\
\hline & GAD-7 scores & 0.74 & 1.03 & 0.86 & 1.24 \\
\hline & PHQ-9 scores & 0.48 & 1.05 & 0.91 & 1.21 \\
\hline & $\mathrm{Age}^{*}$ & $<0.001$ & 0.45 & 0.34 & 0.58 \\
\hline & gender & 0.13 & 2.11 & 0.80 & 5.56 \\
\hline \multirow{3}{*}{$\begin{array}{l}\text { MS-pre (1) vs. HP (0) } \\
\text { (reference level: HP) }\end{array}$} & CPDI scores & 0.27 & 0.96 & 0.89 & 1.03 \\
\hline & GAD-7 scores & 0.39 & 1.11 & 0.87 & 1.42 \\
\hline & PHQ-9 scores & 0.13 & 1.16 & 0.96 & 1.39 \\
\hline
\end{tabular}




\begin{tabular}{|c|c|c|c|c|c|}
\hline & Age* $^{*}$ & $<0.001$ & 0.29 & 0.21 & 0.39 \\
\hline & gender & 0.16 & 2.41 & 0.71 & 8.18 \\
\hline \multirow{5}{*}{$\begin{array}{l}\text { MS-pre (1) vs. HP-COVID (0) } \\
\text { (reference level: HP-COVID) }\end{array}$} & CPDI scores* & 0.01 & 0.90 & 0.84 & 0.97 \\
\hline & GAD-7 scores & 0.14 & 1.20 & 0.94 & 1.52 \\
\hline & PHQ-9 scores* & 0.03 & 1.23 & 1.02 & 1.47 \\
\hline & Age* $^{*}$ & $<0.001$ & 0.30 & 0.22 & 0.40 \\
\hline & gender & 0.72 & 0.80 & 0.24 & 2.68 \\
\hline \multirow{5}{*}{$\begin{array}{l}\text { MS-cli (1) vs. HP (0) } \\
\text { (reference level: HP) }\end{array}$} & CPDI scores & 0.19 & 0.96 & 0.91 & 1.02 \\
\hline & GAD-7 scores & 0.44 & 1.08 & 0.89 & 1.31 \\
\hline & PHQ-9 scores & 0.21 & 1.10 & 0.95 & 1.27 \\
\hline & Age* $^{*}$ & $<0.001$ & 0.64 & 0.56 & 0.73 \\
\hline & gender & 0.78 & 1.14 & 0.46 & 2.86 \\
\hline \multirow{5}{*}{$\begin{array}{l}\text { MS-cli (1) vs. HP-COVID (0) } \\
\text { (reference level: HP-COVID) }\end{array}$} & CPDI scores* & $<0.001$ & 0.91 & 0.86 & 0.96 \\
\hline & GAD-7 scores & 0.12 & 1.16 & 0.96 & 1.40 \\
\hline & PHQ-9 scores* & 0.03 & 1.17 & 1.01 & 1.35 \\
\hline & Age* $^{*}$ & $<0.001$ & 0.67 & 0.58 & 0.76 \\
\hline & Gender* & 0.04 & 0.38 & 0.15 & 0.94 \\
\hline \multirow{5}{*}{$\begin{array}{l}\text { HP (1) vs. HP-COVID (0) } \\
\text { (reference level: HP-COVID) }\end{array}$} & CPDI scores* & 0.02 & 0.94 & 0.90 & 0.99 \\
\hline & GAD-7 scores & 0.43 & 1.08 & 0.90 & 1.29 \\
\hline & PHQ-9 scores & 0.36 & 1.06 & 0.93 & 1.21 \\
\hline & Age* $^{*}$ & 0.04 & 1.04 & 1.00 & 1.07 \\
\hline & Gender* & 0.01 & 0.33 & 0.15 & 0.71 \\
\hline
\end{tabular}

Table 5 - PHQ-9 and CPDI values, and their correlations with gender and age 


\begin{tabular}{|c|c|c|}
\hline \multicolumn{3}{|c|}{ PHQ-9 values, correlations with gender and age } \\
\hline & Gender & Age \\
\hline GP vs. HP-COVID & $r_{s}=-0.23, p=0.001^{*}$ & $r_{s}=-0.28, p<0.001^{*}$ \\
\hline MS-pre vs. HP-COVID & $r_{s}=-0.15, p=0.11$ & $r_{s}=-0.42, p<0.001^{*}$ \\
\hline MS-cli vs. HP-COVID & $r_{s}=-0.26, p=0.004^{\star}$ & $r_{s}=-0.29, p=0.001^{*}$ \\
\hline \multicolumn{3}{|c|}{ CPDI values, correlations with gender and age } \\
\hline & Gender & Age \\
\hline GP vs. HP-COVID & $r_{s}=-0.25, p=0.001^{*}$ & $r_{s}=-0.13, p=0.07$ \\
\hline MS-pre vs. HP-COVID & $r_{s}=-0.30, p=0.001^{*}$ & $r_{s}=-0.19, p=0.04^{\star}$ \\
\hline MS-cli vs. HP-COVID & $r_{s}=-0.32, p<0.001^{\star}$ & $r_{s}=0.04, p=0.65$ \\
\hline HP vs. HP-COVID & $r_{s}=-0.23, p=0.01 *$ & $r_{s}=-0.13, p=0.16$ \\
\hline
\end{tabular}

